\title{
Adapt and thrive: student engagement on a Business and Economics Foundation Year programme during Covid-19
}

\author{
Gerald Dampier \\ University of Surrey, UK
}

Keywords: Covid-19; student engagement; Foundation Year; learning development.

\section{The challenge}

One significant feature of the first sudden lockdown (March 2020) was the immediate downward impact on attendance and engagement in the hastily convened online sessions that followed. This was noted both across the University as a whole and on the Foundation Year programme to which I am attached in a full-time capacity as a Learning Developer, providing embedded subject-specific development input to the whole cohort. As a course team with a relatively high student:staff ratio (approximately 1:25) and with 115 students, we were mindful of the impact that low levels of engagement could have on student achievement (Newman-Ford et al., 2008). We were concerned about the implications for the new 'hybrid' learning context launched in September 2020, with the likely prospect of further fully-online provision. With these issues in mind we designed a robust, researchinformed approach to fostering student engagement.

\section{The response}

The fully embedded nature of my Learning Developer role within a small teaching team (4.7 FTE) allows me to push student-centred and inclusive approaches to learning and teaching on the programme from curriculum design stage onwards. The shifts to hybrid and online interactions provided opportunities to influence programme priorities, with levels of student engagement in mind. 
Defining 'engagement' is not necessarily straightforward, but establishing a shared understanding of the term was important. For 2020-21 we introduced it as a concept to students and stressed its importance from Welcome Week onwards, drawing on the definition by Krause and Coates (2008) of student engagement as 'the extent to which students are engaging in activities that higher education research has shown to be linked with high-quality learning outcomes' (p.493), across academic, non-academic, and social elements. Anticipating disruption to the non-academic and social realms for this year, we particularly stressed academic indicators such as attendance, submission of formative work, communication with staff and classmates, and engagement with personal tutors.

The course team overtly recorded attendance and treated this as a potential indicator of engagement and a factor in achievement. Various studies have established correlations between attendance and achievement: particularly relevant to our context in both level and subject area is the one by Halpern (2007) of first-year business students. This year (non-) attendance became an agenda item for weekly staff meetings and enabled the implementation of a more nuanced, multi-pronged pastoral follow-up policy than previously. Low attendees received communications from course tutors, faculty administration, and the university's Student Success team, depending on the frequency of absence. Around 20 students were identified as low engagers at different stages, and only four of these remained significantly detached by the programme end.

As Learning Developer, I was able to influence the nature of personal tutor meetings. These were previously inconsistent, with some tutors working with students one-to-one and others inviting students to 'opt-in' to group meetings of 15 or more. I drew tutors' attention to relevant literature, such as Briggs, Clark and Hall (2012), which stresses the importance in transition of small group and one-to-one interactions between students and academic staff, and Grey and Osborne (2018), which notes the contribution of such encounters to student belonging, retention, and success. Students were set a nonassessed written reflection task on their motivations for joining the programme, designed to allow them to share academic and/or more personal information with the personal tutor, intended to inculcate a sense of personal connection with the university: $85 \%$ of students submitted this. One-to-one meetings with personal tutees began from week three. These were not time-consuming (15 minutes per semester, although some needed re-scheduling, sometimes more than once). While not all tutors bought into the approach until Semester 
Two, it was noticeable from then that students no longer commented that they did not know their personal tutor.

In the absence of much of the usual face-to-face contact that students benefit from under normal circumstances both inside and outside class, the year-long group assessed module took on particular significance and was noticeably uncompromised by the move from hybrid to fully online. Failures of group work were significantly fewer this year than previously, perhaps because of the combination of effective structure, support, and the lack of alternative social activity; students were quick in conversational feedback to identify this task as enjoyable and successful both on an academic and a social level. The wider benefits reflected those identified by the Eberly Centre (2021), whose report highlights how 'positive group experiences ... contribute to student learning, retention and overall college success', i.e., beyond either the module or programme itself.

Further results, in terms of the performance indicators identified above, were pleasing. Formative work was submitted at levels above previous years, e.g., by $77 \%$ of students on the Research Project module. A 'snapshot' of live online attendance early in Semester 2 shows all seminar groups with $70+\%$, and several in the $80-100 \%$ range. These figures are significant not only for being slightly higher than previously but also because attendance and engagement were reported as positive across all Foundation streams in contrast with widespread concerns on many programmes at levels 4-6. Reasons for this difference across year groups are not entirely clear but a connection with the student-centred and scaffolded nature of learning and teaching on the Foundation Programmes generally would seem plausible.

\section{Recommendations}

The approaches outlined above were largely honed in response to pandemic conditions and informed by learning development, but are widely transferrable. These included agreeing a workable definition of 'engagement' with staff and students in the hybrid context, using an evidence-informed approach to emphasise interactions between personal tutors and students, student-to-student communication in group-work, and tightening approaches to responding to absence. It is important to note (Newman-Ford et al., 2008) that while 'attendance' should not be equated directly with 'engagement', non- 
attendance is nonetheless a possible indicator of disengagement and teams should address concerns with a structured approach.

Learning Developers can help ensure that individual students' communications with staff, other students, and the institution are effective. For us this meant personal tutors being proactive in contacting students, then reporting back if a response was not forthcoming; module tutors supporting group-work and being willing to respond to patterns of absence by contacting students in a timely manner; for the team as a whole to coordinate nuanced responses to absence, i.e., through a mixture of concern and 'strong words', involving other university services when appropriate.

Overall, our experience suggests that teaching teams need to respond to context. Learning Developers can recognise times of change as opportunities to influence engagement levels, especially when such roles are well embedded. Adaptability is important: while many of the practices established in the pandemic are sound and sustainable, further change may be necessary when social and non-academic dimensions of universities grow again.

\section{References}

Briggs, A. R. J., Clark, J. and Hall, I. (2012) 'Building bridges: understanding student transition to university', Quality in Higher Education, 18(1), pp.3-21. https://doi.org/10.1080/13538322.2011.614468.

Eberly Centre (2021) What are the benefits of group work? Available at:

https://www.cmu.edu/teaching/designteach/design/instructionalstrategies/groupprojec ts/benefits.html (Accessed: 24 May 2021).

Grey, D. and Osborne, C. (2018) 'Perceptions and principles of personal tutoring', Journal of Further and Higher Education. Available at: http://ray.yorksj.ac.uk/id/eprint/3417/ (Accessed: 24 May 2021).

Halpern, N. (2007) 'The impact of attendance and student characteristics on academic achievement: findings from an undergraduate business management module', 
Journal of Further and Higher Education, 31(4), pp.335-349.

https://doi.org/10.1080/03098770701626017.

Krause, K. and Coates, C. (2008) 'Students' engagement in first-year university', Assessment \& Evaluation in Higher Education, 33(5), pp.493-505. https://doi.org/10.1080/02602930701698892.

Newman-Ford, L., Fitzgibbon, K., Lloyd, S. and Thomas, S. (2008) 'A large-scale investigation into the relationship between attendance and attainment: a study using an innovative, electronic attendance monitoring system', Studies in Higher Education, 33(6), pp.699-717. https://doi.org/10.1080/03075070802457066.

\section{Author details}

Gerald Dampier is a Teaching Fellow in Learning Development at the University of Surrey. $\mathrm{He}$ is employed within the Academic Skills and Development function of the Library and Learning Services and attached full-time to the Foundation Year programme in Business, Management and Economics. 